\title{
Two Beer(s) or Not Two Beer(s): The eNose as an Instrument to Pacify the World
}

\section{Two Beer(s) or not two Beer(s): Die eNose als ein Instrument zur Befriedung der Welt}

\section{두(우요 $\odot$}

\author{
Authors \\ Matthias Volkmar Kopp ${ }^{1,2}$, , Markus Weckmann², 3, Gyde Nissen², 3, Isabell Ricklefs², 3, Christoph Härtel ${ }^{4}$
}

\section{Affiliations}

1 University Clinic for Pediatrics, Inselspital University Bern, Bern, Switzerland

2 Member of the Deutsches Zentrum für Lungenforschung (DZL), Airway Research Center North (ARCN), Luebeck, Germany

3 Department of Pediatric Pulmonology and Allergy, University of Luebeck Human Medicine, Lubeck, Germany

4 Direktor der Kinderklinik und Poliklinik, JuliusMaximilians-Universität Würzburg Medizinische Fakultät, Wurzburg, Germany

\section{Key words}

electronic nose, beer, fake and reality, Gesellschaft

Pädiatrische Pneumologie, paediatrics

\section{Schlüsselwörter}

elektronische Nase, Bier, Fake und Realität, Gesellschaft Pädiatrische Pneumologie, Pädiatrie

published online $\quad 09.02 .2022$

\section{Bibliography}

Klin Padiatr 2022; 234: 301-304

DOI 10.1055/a-1714-8895

ISSN $\quad 0300-8630$

(c) 2022. Thieme. All rights reserved.

Georg Thieme Verlag, Rüdigerstraße 14,

70469 Stuttgart, Germany

\section{Correspondence}

Prof. Matthias V. Kopp

Inselspital Universitatsspital Bern

University Clinic for Pediatrics

Freiburgstrasse 15

3010 Bern

Switzerland

Tel.: + 41/316/641 351,

matthias.kopp@insel.ch

\begin{abstract}
Background Science prizes that are not meant to be very serious, stand-up evenings, science slams or publications with a scientific twist: science comedy comes in very different forms. But all variants have one thing in common: humour. It can be used to hide the seriousness of life or, in this case, everyday scientific life for a brief moment. Moreover, serious social or ethical questions are also met. The GPP, a group of German, Austrian and Swiss Pediatric Pulmonologists (GPP) is a scientific society with regular annual meetings. Unsystematic observations and preliminary data suggest that beer consumption increased by some of the participants during this event. Recently, electronic nose (eNose) devices have been developed as a technology for disease screening using exhaled-breath analysis. Here we addressed the issue, if the eNose can be used to differentiate between real beer and fake beer.

Methods In this single-centre experimental study, 12 different "real beer" types and one "fake beer" were analyzed with regard to their emittance of volatile organic compounds (VOCs) with the eNose as an electronic VOC-sensing technology. Results Every single beer type can be identified by a characteristic VOC-smell print using the eNose. Distinct clusters exist for bottom- and top-fermented ales. Intriguingly, "Sylter Hopfen", which is marketed as a "champagne-beer" and tested as representative of a "fake beer", can be clearly differentiated from all other genuine beer types.

Conclusion Our study provides the first objective data of beer flavor. In the long term perspective the eNose might help to overcome the agonizing controversy about beer flavors and, consequently, pacify the World. In the short run, however, our results give support to more targeted and reserved beer consumption during our annual meeting, especially since one specific beer shows a very similar pattern to indoor air.
\end{abstract}

\section{ZUSAMMENFASSUNG}

Hintergrund und Fragestellung Sogenannte Stand-upAbende, Science Slams oder Publikationen wie in der «Christ- 
mas-Edition» des "British Medical Journals" haben eines gemeinsam: Humor. Humor kann dabei helfen, der Ernsthaftigkeit des Alltags - auch der des Wissenschaftlers - für einen kurzen Moment zu entfliehen. Die wissenschaftliche Gesellschaft Pädiatrische Pneumologie (GPP e. V.) ist eine Gruppe deutscher, österreichischer und schweizer Kinderpneumolog:innen, die sich regelmässig zu ihrer Jahrestagung treffen. Nicht-systematisch erhobene Daten und persönliche Beobachtungen deuten darauf hin, dass der Bierkonsum von einigen der Teilnehmer: innen während dieser Veranstaltung signifikant ansteigt. Vor kurzem wurde mit der «eNose» eine sogenannte «elektronische Nase» entwickelt, die als Screening-Instrument zur Atemgasanalyse eingesetzt werden kann. Hier haben wir die Frage gestellt, ob die eNose verwendet werden kann, um unterschiedliche Biersorten zu unterscheiden und echte Biere von sogenannten «Fake-Bieren» zu diskriminieren.

Methoden In dieser monozentrischen, experimentellen Studie wurden 12 verschiedene „echte Biersorten“ und ein
„Fake-Bier“ hinsichtlich ihrer Emission flüchtiger organischer Verbindungen (VOCs) mit der eNose als elektronische VOCSensortechnologie analysiert.

Ergebnisse Jede einzelne Biersorte lässt sich anhand eines charakteristischen, reproduzierbaren VOC-Profils mit der eNose identifizieren. Dabei clustern sogenannte unter- und obergärige Biere mit einem spezifischen Muster. „Sylter Hopfen“, das als „Champagner-Bier“ vermarktet und als «Fake-Bier» getestet wurde, unterscheidet sich in seinem VOC-Profil von allen anderen «echten» Biersorten.

Schlussfolgerung Unsere Studie liefert die ersten objektiven Daten zu spezifischen VOC-Mustern von verschiedenen Biersorten. Langfristig könnte die eNose dabei helfen, die emotionale Kontroverse um Bieraromen zu überwinden und damit die Welt zu befrieden. Kurzfristig stützen unsere Ergebnisse die Empfehlung nach einem zurückhaltenden Bierkonsum während unserer Jahrestagung, zumal spezifischen VOC-Mustern einiger Biere ein sehr ähnliches Muster wie Raumluft zeigen.

\section{Introduction}

Beer is an essential and perhaps the only presentable part of German culture - apart from football [1].

As there is no pleasure without restrictions and regulations, the German Beer Purity Law from 1516 determines that only hops, barley and water are to be used for brewing beer. Despite the limited number of ingredients German brewers have managed to create over 5,500 different ales. In parallel, there are an increasing number of (micro-) breweries not only in Germany, but all over the world. Obviously, the history of German beer parallels the history of particularism, nationalism and protectionism. To prevent that "Germany's Beer first", as old as the German Beer Purity law, receives the status of "alternative facts", there is an urgent need to establish objective measures of what is a genuine beer and what is a fake beer. Overcome falsehood with truth is the way of peace, as former US president Abraham Lincoln previously indicated: "I am a firm believer in the people. If given the truth, they can be depended upon to meet any national crisis. The great point is to bring them the real facts."

Over the past years, "electronic sensing" technologies were developed and used for medical-diagnostic applications [2-5]. The eNose is able to identify the specific components of an odor, i. e. its content of volatile organic compounds (VOCs) by analyzing air with the help of sensor arrays and pattern recognition systems. We hypothesized that the eNose can differentiate 1) between different beer types and 2) between genuine "real" beer and fake beer. Therefore we tested different genuine (i. e. Pils, Lager, Ale) beers from different countries as well as "Sylter Hopfen" (champagnebeer) as representative of a "fake beer". This beer is fermented in two steps: the first step is a bottom-fermented process; the second is comparable to a champagne production in the bottle.

Our study provides the first objective data of easy to perform detection of volatile beer flavor, which might overcome the centuries-old controversy about beer types.

\section{Methods}

The study originated during a scientific meeting in Amsterdam, The Netherlands, and was conducted in the meeting room of the laboratory building (House 50), a classic concret building from the 1970s, at the University Hospital in Luebeck (Germany). The adequate disposal of beer by the investigators at the end of the experiments was mandatory. Out of five investigators (age range 23 - 53 years), two were females and all of them were non-smokers. Once we had invited one member of the ethical committee to witness our experiments, no formal ethics and written informed consent was necessary for our studies.

\section{Beer Types}

We tested four different beer types of "genuine" beer from five different countries. Beers no 1 - no 10 were bottom-fermented beers (Pils, Lager and Märzen beers), fermented at $8-11^{\circ}$ Celsius. Beers no 11 and 12 were top-fermented beers, fermented at $14-22^{\circ} \mathrm{Cel}-$ sius. Additionally, we tested "Sylter Hopfen”, marketed as a "gourmet-" or "champagne-" beer, which naturally served as un-healthy control ("fake" beer). An overview is given in > Table $1[6,7]$.

\section{eNose}

Measurements were performed using the Cyranose 320 (Sensigent, Baldwin Park, California, USA). With this device, VOC measurements are based on a change in resistance of each nanocomposite array sensor (i. e. conducting particles embedded in an insulating polymer) in a 32-sensor array (nose chip) when exposed to beer vapor. Reference measurements were each replicated after testing of three beer types in a row. All beer bottles were subsequently opened in a standardized way and the eNose measurements were performed immediately in triplicates according to established standardized operating procedures (SOPs) and thus under strict quality control. All experiments were performed the same day. Any differential sensor response is measured as $\left(R_{\max }-R_{0}\right) / R_{0}$, with $R_{0}$ being the resistance of the respective sensor during reference 
- Table 1 Characteristics of the different beer types tested in our study. n.i. = no information available; n/a not applicable. IBU: international bitterness units $[6,7]$.

\begin{tabular}{|l|l|l|l|l|l|l|}
\hline No & NAME & TYP & $\begin{array}{l}\text { ALCO- } \\
\text { HOL } \% \text { o }\end{array}$ & $\begin{array}{l}\text { ORIGINAL } \\
\text { GRAVITY }\end{array}$ & IBU & Origin \\
\hline 1 & Astra Urtyp & Bottom-fermented, Pils & 4.9 & $11 \%$ & 28 & Hamburg, Germany \\
\hline 2 & Becks Pils & Bottom-fermented, Pils & 4.9 & $11.2 \%$ & 28 & Bremen, Germany \\
\hline 3 & Flensburger Pilsner & Bottom-fermented, Pils & 4.8 & n.i. & 38 & Flensburg, Germany \\
\hline 4 & Jever Pilsner & Bottom-fermented, Pils & 5.0 & $11.2 \%$ & 40 & Jever, Germany \\
\hline 5 & Klüvers Pils & Bottom-fermented, Pils & 4.8 & n.i. & 23 & Neustadt, Germany \\
\hline 6 & Ricklinger Pils & Bottom-fermented, Pils & 4.8 & n.i. & 45 & Rickling, Germany \\
\hline 7 & Ricklinger Märzen & Bottom-fermented, Märzen-Beer & 5.5 & $14 \%$ & n.i. & Rickling, Germany \\
\hline 8 & Stiegl Goldbräu & Bottom-fermented, Märzen-Beer & 4.9 & $12 \%$ & 20 & Salzburg, Austria \\
\hline 9 & Samuel Adams Boston & Bottom-fermented, Lager-Beer & 4.9 & $13 \%$ & 30 & Boston, USA \\
\hline 10 & Lille Lager & Bottom-fermented, Lager-Beer & 5.7 & $13.5 \%$ & 27 & Kiel, Germany \\
\hline 11 & Browar Bednary Holy Grale & Top-fermented, American Pale Ale & 4.6 & n.i. & 40 & Bednary, Poland \\
\hline 12 & Jopen Ongelovige Thomas & Top-fermented, American Strong Ale & 10.0 & n.i. & 40 & Haarlem, The Netherlands \\
\hline 13 & Sylter Hopfen & Champagne-Beer & 7.1 & $17.6 \%$ & N/A & Flensburg, Germany \\
\hline
\end{tabular}

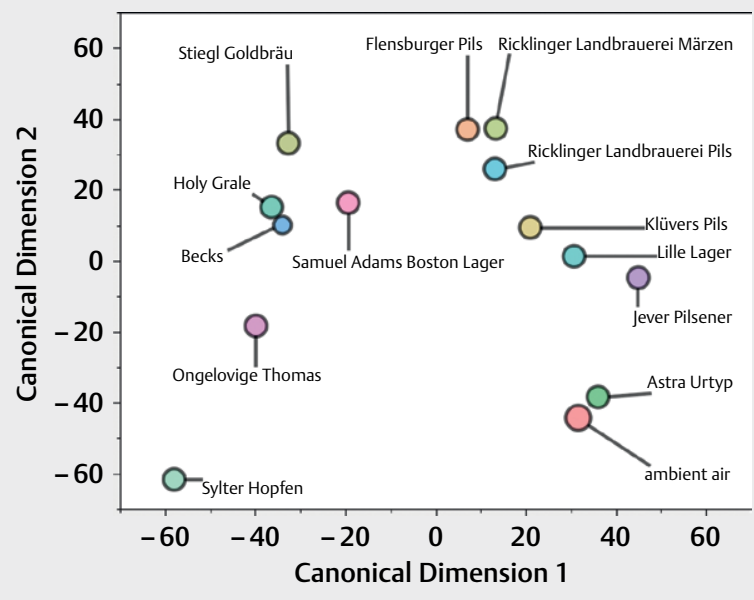

Fig. 1 Bubble graph illustrating the results of the discrimination analysis. Bubbles represent a mean distance of three independent technical replicates of e-Nose measurements of the beer types. The closer the bubbles are the more similar the smell print of the beer.

gas flow (VOC-filtered ambient air) and $R_{\max }$ being the maximum resistance during exposure to each beer sample vapor. Using proprietary pattern-matching algorithms, data were then converted into response patterns which were exported as raw data.

\section{Results}

As illustrated in > Fig. 1, a characteristic smell-print was assigned to each beer using the eNose exactly differentiating between different beer types. While bottom-fermented beers (Pils, Lager and Märzen Beers) predominantly clustered in the right and left upper square (except No2 and No9), the top fermented beers clustered in the left squares of the PCA plot. The signal from Astra Pilsner was very close to the measured signal of ambient air. eNose values showed a high reproducibility across the beer triplicates.
Moreover, "Sylter Hopfen", which is marketed as a "champagneBeer" and which was tested as a representative of a "fake beer" can be clearly differentiated from all other real beer types and ambient air.

\section{Discussion}

"Oh, about beer I never lie”, Crandall said. "A man who lies about beer makes enemies." [US author Stephen King in Pet Sematary: A Novel (1983)].

We have demonstrated for the first time, that the eNose is an objective measure to discriminate real beer from fake beer. Moreover, the eNose can also differentiate between specific beer types according to fermentation process. Interestingly, the national allocation of different beer types showed no specific clustering. Our results cannot be valued high enough, since the clash of different beer cultures constantly induces a beer crash and serves as a reason for international conflicts. In 2021, 500 years after reformation, we need to acknowledge that Luther' s words: "peace if possible, truth at all costs" are still problematic political labels. In our hands, eNose has an excellent cost-benefit ratio to obtain and communicate real facts. As an example, Sylter Hopfen (“fake beer") was clearly distinguishable from every other "real beer". The eNose might therefore become an objective instrument to discriminate between fake and reality independent of a personal assessment, a specific "beer mood" or other confounding variables (apart from football). Up to now, our findings are limited to beer flavors but the reliability of data indicate that eNose may provide a valuable point-of-interest measure to shed light on various global controversies.

The smell-print originating from Astra was very close to the smell-print of the ambient air. This finding needs further explanation. One possibility is that the flavor of Hamburg's Astra Pilsner is very weak (and so is the performance of Hamburg's football teams HSV and St. Pauli). In this circumstance, the eNose is not sensitive enough to detect any signal. However, researchers (MVK, GN, CH) independently certified that Astra has a characteristic odor which is very much distinct from fresh air. An alternative explanation would be that the ambient air was already saturated with the Astra 
beer volatiles so that the eNose allocates the ambient air signal near by the Astra signal. This explanation is more likely, hence a high number of meetings are tightly synchronized by time in the conference room and regular beer consumption by frustrated researchers can-not be ruled out.

Our study has certain strengths including repeated measurement of eNose signals and the straight-forward study protocol with rigorous quality controls. One limitation is the small number of tested beer types. However, as we had no public funding, our financial resources were limited. Based on ethical reasons we refrained from external funding by brewing companies. Moreover, the disposal of measured beer by the investigators at the end of the experiments leads to a significant loss of working capacity during the following days. As this had to be limited, we finally decided to select only representative beer species, thus balancing knowledge production and duty of care for the scientific community.

Moreover, one might wonder whether we haven 't considered to include British beers in our study, i. e. Ale, Porter or Stout. Besides a controversy in our study team, whether British beer has to be classified as "real" or "fake" beer, we felt that the sobering Brexit discussion might counteract our beer message of peace.

Another possible weakness of our study is the fact that we did not include any of the many tasty Bavarian beers. The Bavarian beer market is characterized by a particularly large variety of types ( $>40$ beer types) compared to other federal states in Germany (https:// www.bayrisches-bier.de/bier-wissen/die-biersirten/). Since there is still no consensus about the one representative Bavarian beer and, for reasons of feasibility, not all 40 Bavarian beer types could be considered, we decided to exclude Bavarian beers from our study.

Finally, a potential observer bias needs to be discussed, as pediatricians are professional pacifiers with a genuine urge to appease the world and are obsessed with non-invasive measuring options. For example, the non-invasive assessment of neonatal jaundice severity is still based on a tintometer - a color scale that was initially designed for the brewing industry to evaluate the quality of beers [8]. Therefore, eNose is considered to be highly attractive to medical doctors who have to rely on a "good clinical nose" and their gut feeling rather than evidence-based medicine [9].

Future studies 1) should include a broader range of beer types, i. e. from Bavaria, Austria and Switzerland; 2) have to compare objective eNose data with subjective assessments of beer drinkers and drinking habits; and 3) need to assess eNose patterns for the odor of beer drinkers stratified to quantity and speed of beer consumption, age, gender, ethnical background and - of course - football season. These data will clarify, if our results can be transferred to everyday life.

Taken together, our study provides the first objective data of beer flavor, which might overcome the controversy about beer types. As pediatricians and professional pacifiers we are convinced, that our findings might contribute to a peaceful and unified world in the long-term perspective. In the short run, however, our results give support to more targeted and reserved beer consumption during our scientific annual meeting, especially since one specific beer shows a very similar pattern to indoor air.

\section{Authors Contribution}

MVK and $\mathrm{CH}$ wrote the manuscript. MW and $\mathrm{GN}$ reviewed the manuscript, even though they were responsible for the adequate disposal of beer at the end of the experiments. MVK and MW designed the study protocol. MW and GN performed the eNose measurements. MVK, MW and $\mathrm{CH}$ analyzed the data. MVK and MW sponsored the beer.

\section{Acknowledgements}

This article is specifically dedicated to Prof. Dr. Bodo Niggemann, former head of the Department of Pediatric Respiratory Medicine and Immunology, Charite, Berlin. He is an honorary member of the Pediatric Pulmonology Society (Gesellschaft Pädiatrische Pneumologie GPP e.V.), a great clinician, researcher and teacher, member of the band “Echte Ärzte", a passionate wine drinker, and last but not least a good friend. In addition, this article is dedicated to all friends and colleagues at the Inselspital in Bern, the University Hospital SchleswigHolstein in Luebeck and the University Clinic in Würzburg, who with their warm advice and benevolent support have prevented us from drinking too much beer. Special thanks go out in deep connection to the coffee group in Lübeck, namely to Wolfgang Göpel, Egbert Herting, Thorsten Langer and Melchior Lauten, for many stimulating discussions that broadened our horizons. We would like to thank Stefan Tümmers and Oliver Fuchs for their contribution to the implementation of the eNose measurements in Lübeck.

\section{Conflict of Interest}

The authors declare that they have no conflict of interest.

\section{References}

[1] https://de.wikipedia.org/wiki/Kultur_Deutschlands\#Küche (last visit November 17th 2021)

[2] Brekelmans MP, Fens N, Brinkman P, Bos LD, Sterk PJ, Tak PP, Gerlag DM. Smelling the Diagnosis: The Electronic Nose as Diagnostic Tool in Inflammatory Arthritis. A Case-Reference Study. PLoS One 2016; 11: e0151715

[3] Dragonieri S, van der Schee MP, Massaro T, Schiavulli N, Brinkman P, Pinca A, Carratú P, Spanevello A, Resta O, Musti M, Sterk PJ. An electronic nose distinguishes exhaled breath of patients with Malignant Pleural Mesothelioma from controls. Lung Cancer 2012; 75 : 326-331

[4] Dragonieri S, Pennazza G, Carratu P, Resta O. Electronic Nose Technology in Respiratory Diseases. Lung 2017; 195: 157-165

[5] Plaza V, Crespo A, Giner J, Merino JL, Ramos-Barbón D, Mateus EF, Torrego A, Cosio BG, Agustí A, Sibila O. Inflammatory Asthma Phenotype Discrimination Using an Electronic Nose Breath Analyzer. J Investig Allergol Clin Immunol 2015; 25: 431-437

[6] https://bier-index.de (last visit November 17th 2021)

[7] https://untapped.com (last visit November 17th 2021)

[8] Rowntree LG, Brown G. A tintometer for the analysis of the color of the skin. American Journal Medical Science 1925; 170: 341

[9] Van den Bruel A, Thompson M, Buntinx F, Mant D. Clinicians' gut feeling about serious infections in children: observational study. BM] 2012; 345: e6144 